\title{
Computational Modelling of Failure Mechanisms in Fibre Metal Laminates
}

\author{
$\underline{\text { Ibrahim H. Abuzayed }}^{1 *}$, Ahmed Saadi ${ }^{2}$, Jose L. Curiel-Sosa ${ }^{1}$ \\ ${ }^{1}$ Department of Mechanical Engineering, The University of Sheffield, Sheffield, United Kingdom \\ ${ }^{2}$ Composite Centre, The Advanced Manufacturing Research Centre, The University of Sheffield, \\ Wallis Way, Catcliffe, S60 5SR \\ *ihabuzayed1@sheffield.ac.uk
}

Fibre Metal Laminates (FMLs) are hybrid materials that are composed of thin metal layers reinforced with unidirectional or bi-directional fibre composites. The most common type of FMLs is the glass laminate aluminium reinforced epoxy (GLARE) which comprised aluminium and prepreg layers. FMLs benefit from the properties of both constituents, they are characterised by their low weight, high strength and excellent fatigue resistance [1]. The superior mechanical properties of FMLs made them attractive to the aerospace industry, for example, GLARE is used for the manufacture of the fuselage and leading edges of A380 [1].

FMLs were originally developed to improve the fatigue damage growth resistance of the monolithic metals used for aerospace structures such as aluminium. According to $\mathrm{Wu}$ and Yang GLARE shows 10 to 100 times slower crack growth rates compared to Aluminium [2]. The fatigue failure in FMLs, as described by Alderliesten [3], begins with crack initiation and propagation under cyclic loading in a metallic layer followed by delamination between the metal and composite interface. The delamination distributes the stress caused by the cyclic loading over a larger area which decreases the stress in the composite layers and decreases the risk of composite failure i.e. (matrix cracking or fibre splitting) [4]. Therefore, the fibres remain intact and allow the load to be transferred through the composite layer across the crack [3]. This is often referred to as the bridging mechanism, where it plays a significant role in decreasing the crack growth in FMLs.

In the current work, a unit cell will be used to investigate the failure mechanisms of FMLs. A mesoscale finite element model with a representative $3 \mathrm{D}$ unit cell will be constructed and tested under various loading conditions with the commercial finite element software ABAQUS. The failure of FMLs will be investigated using different numerical methods such as the extended finite element method (XFEM) [5, 6]. The crack growth in FMLs will be predicted and the results will be verified with experimental results from the literature.

\section{References}

[1] Chang, P. Y. and Yang, J. M. (2008) Modeling of fatigue crack growth in notched fiber metal laminates. International Journal of Fatigue, 30, 2165-2174.

[2] Wu, G. and Yang, J. M. (2005) The mechanical behavior of GLARE laminates for aircraft structures. Jom, 57, 72-79.

[3] Alderiesten, R. (2019) Fatigue in fibre metal laminates: The interplay between fatigue in metals and fatigue in composites. Fatigue and Fracture of Engineering Materials and Structures, 42, 2414-2421.

[4] René C. Alderliesten (2017) Fatigue and Fracture of Fibre Metal Laminates. Edited by U. J.R. Barber, Ann Arbor and S. Anders Klarbring, Linköping. Springer.

[5] Curiel Sosa, J. L. and Karapurath, N. (2012) Delamination modelling of GLARE using the extended finite element method. Composites Science and Technology. Elsevier Ltd, 72, 788-791.

[6] Curiel-Sosa JL, Tafazzolimoghaddam B \& Zhang C (2018) Modelling fracture and delamination in composite laminates: Energy release rate and interface stress. Composite Structures, 189, 641-647. 